\title{
Using a Mindfulness-Based Intervention to Support the Resiliency of In-Patient Pediatric Respiratory Therapists
}

\author{
Julie Luzarraga, Christopher Wichman, Rachel Shirk, Cheryl Jarosz, and Meaghann S Weaver
}

\begin{abstract}
BACKGROUND: Respiratory therapists (RTs) are care providers in highly stressful work environments with limited time and resources for self-care. Mindfulness-based interventions teach non-reactive awareness to the present situation or the ability to respond versus react in the moment, to shift away from a physical and emotional stress response. METHODS: Mindfulness-based group learning was offered during 2 regularly scheduled RT staff meetings for $\sim 30$ min each session. Each meeting began and concluded with a distress assessment and with counting and recording respirations for 30 s. RESULTS: This quality-improvement project revealed mindfulness-based interventions to be feasible and acceptable. Mindfulness intervention reduced RT team members' physical and emotional stress related symptoms (as measured by a 1-point median decrease in the self-administered distress assessment, with $P=.001$ in session 1) and increased sense of calm (as measured by participant breathing rate decrease by mean of two-points $P=.001$ in session 1 and session 2). CONCLUSIONS: Mindfulness-based interventions were noted to be feasible and acceptable additions to RT staff meetings. These interventions have the potential to introduce breathing practices and mini mindfulness techniques. Key words: mindfulness based intervention; respiratory therapy; professional resiliency; pediatric palliative care. [Respir Care 2019;64(5):550-554. (C) 2019 Daedalus Enterprises]
\end{abstract}

\section{Introduction}

Respiratory therapists (RTs) are care providers in highly stressful work environments with limited time and resources for self-care. ${ }^{1}$ Despite the high levels of work-related stress, RTs must attend to pediatric patients, family members,

\footnotetext{
Ms Luzarraga is affiliated with Omaha Integrative Care, Omaha, Nebraska. Dr Wichman is affiliated with the Department of Biostatistics, University of Nebraska Medical Center, Omaha, Nebraska. Ms Shirk and Ms Jarosz are affiliated with Division of Respiratory Therapy, Department of Pediatrics, Children's Hospital and Medical Center Omaha, Omaha, Nebraska. Dr Weaver is affiliated with the Division of Palliative Care, Department of Pediatrics, Children's Hospital and Medical Center Omaha, Omaha, Nebraska.
}

The study was performed at the Children's Hospital and Medical Center Omaha, Omaha, Nebraska.

The authors have disclosed no conflicts of interest.

Correspondence: Meaghann S Weaver MD MPH, Hand in Hand/Division of Palliative Care, Children's Hospital and Medical Center Omaha, 8200 Dodge Street, Omaha, NE 68114. E-mail: MeWeaver@ childrensomaha.org.

DOI: $10.4187 /$ respcare.06483 and other providers with compassion and professionalism. In our freestanding children's hospital, RTs compassionately spend hours at the bedside of children who are critically ill as they provide pulmonary care for the child and a supportive presence for the patient's parents. RTs work throughout the hospital and provide life-sustaining and life-saving respiratory treatments for pediatric patients in the emergency department, out-patient clinic, in-patient setting, home health environment, and critical care units. Although core competencies of RTs include "the diagnosis and treatment of acute and chronic respiratory failure to include invasive and noninvasive respiratory therapy,"2 pediatric RTs also focus on symptom management as they care for children at the end of life in palliative care and hospice settings, with attentiveness to excessive secretion management, bronchoscopic airway clearance, inhalation therapies, and oxygen support for comfort. Pediatric RTs thus navigate between life-sustaining and comfort-compelling circumstances.

A survey of 271 RTs in Nebraska (this study occurred in the only freestanding children's hospital in the state) revealed that RTs were generally satisfied with their jobs, with a mean \pm SD Minnesota Satisfaction Questionnaire score of $73.46 \pm 11.63$, although there was noted recog- 


\section{Mindfulness to Support RT Resiliency}

nition of the intensity and stress associated with the duties of RT service. ${ }^{3}$ Increased demands on the job, with high patient caseloads, burnout or compassion fatigue, feeling isolated, a perceived lack of support from supervisors, and lack of job satisfaction are noted factors that contribute to on-site stressors for in-patient RT work. ${ }^{4,5}$

The time frame that our hospital RT personnel needed to complete or re-certify their professional certification fell during the high acuity of winter months. Our study team recognized that many RTs were working overtime to support one another in their roles during this high-stress, busy season at work. To foster self-care and to decrease stress among the members of the RT team, we developed a mindfulness-based intervention to roll out during $2 \mathrm{RT}$ staff meetings. The intervention was titled Pneuma Care, in honor of pneuma, Greek for the vital spirit, soul, or creative force of a person. Mindfulness-based interventions teach non-reactive awareness to the present situation or the ability to respond versus react in the moment, to shift away from a physical and emotional stress response. Mindfulness-based interventions have been shown to decrease stress, improve job fulfillment, enhance professional resiliency, and improve career satisfaction in nurses and other health-care personnel. ${ }^{6-10}$ The purpose of this quality-improvement project was to explore the feasibility and acceptability of mindfulness-based interventions as part of the RT staff meetings to help RT team members relax and de-stress. This quality-improvement project hypothesized that integration of mindfulness-based interventions as part of RT staff meetings would decrease RT team members' physical and emotional stress-related symptoms (as measured by a self-administered Distress Thermometer Assessment) and increase a sense of calm (as measured by participant's breathing rate).

\section{Methods}

The mindfulness-based interventions included group learning during 2 regularly scheduled RT staff meetings for $\sim 30 \mathrm{~min}$ at a freestanding children's hospital in Omaha, Nebraska. The institutional review board determined that the proposal was exempt from full review due to the quality-improvement nature of the project and de-identified participant information. The mindfulness-based interventions session content is summarized in Table 1. The November 2017 and March 2018 sessions both included teaching and practicing a mindfulness respiratory technique. The interventions were not formally validated in the specific context of the respiratory therapy team use but have been validated by consensus method among primary care health professions ${ }^{11}$ and in the general population. ${ }^{12}$ Each meeting opened and concluded with a Distress Thermometer assessment. ${ }^{13}$ The Distress Thermometer is a 10-point scale of a person's level of distress in the moment and has

\section{QUICK LOOK}

\section{Current knowledge}

Respiratory therapists who work in pediatric settings face high levels of stress and intense biomedical scenarios. Mindfulness-based interventions have been shown to decrease stress, improve job fulfillment, enhance professional resiliency, and improve career satisfaction in nurses and other health care personnel, but these interventions have not been reported in the respiratory therapy setting.

\section{What this paper contributes to our knowledge}

Mindfulness-based interventions decreased respiratory therapists' distress and calm respiratory therapists' own breathing rates. Mindfulness-based interventions are a feasible and acceptable integration in respiratory therapists' staff meetings.

been validated as a stress assessment tool in the healthcare settings. ${ }^{14-16}$ The sessions included counting and recording respirations for $30 \mathrm{~s}$. The counting of respirations also served as a grounding point for the start and end of each session. Scales were administered on the same day before and after intervention.

During session 1, the facilitator provided a brief overview of mindfulness practice by using Jon Kabat-Zinn's definition of mindfulness as "paying attention in a particular way: on purpose, in the present moment, and nonjudgmentally." The benefits of mindfulness (improved memory and focus, strengthening the ability to respond vs react, emotion regulation, decreased anxiety and depression, and improved immune functioning) were briefly highlighted. The technique for session 1 was to observe selfbreath. The participants were instructed to take a comfortable but open posture with the shoulders relaxed away from the ears, chest open, and feet grounded on the floor. The facilitator then guided them in noticing the quality of their breathing, noticing where the breath was felt, the texture, the depth, and so forth. One example was to notice that the breath feels cool coming in through the nostrils and warm on exhaling. Time was allowed for any questions or comments. The participants were then given Biodot cards (Biodot (C) 2009 StressStop/AudioVision Inc., Norwalk, Connecticut) to use as simple indicators of their stress level. Biodots are a basic biofeedback tool that measures the temperature of the skin as an indicator of stress. The participants were encouraged to use these throughout the day as a means of beginning to pay attention to stress levels. In addition, the participants were given colored sticky dots to place in areas they frequent as a reminder to breathe mindfully. 


\section{Mindfulness to Support RT ResilienCy}

Table 1. Respiratory Therapy Mindfulness-Based Interventions

\begin{tabular}{|c|c|c|}
\hline Session & Theme & Training Exercise \\
\hline 1. "Essential Breath" & $\begin{array}{l}\text { "Breath is the bridge which connects life to consciousness, which } \\
\text { unites your body to your thoughts. Whenever your mind becomes } \\
\text { scattered, use your breath as the means to take hold of your mind } \\
\text { again." Thich Nhat Hanh }\end{array}$ & $\begin{array}{l}\text { Brief overview of the research on mindfulness, } \\
\text { including breathing exercises } \\
\text { Observing breath } \\
\text { Body scan }\end{array}$ \\
\hline 2. "Being Present" & $\begin{array}{l}\text { "If we hope to go anywhere or develop ourselves in any way, we can } \\
\text { only step from where we are standing. If we don't really know } \\
\text { where we are standing. . . We may only go in circles." Jon } \\
\text { Kabat-Zinn }\end{array}$ & $\begin{array}{l}\text { Brief check-in } \\
2: 1 \text { Breathing practice } \\
\text { Mindfulness breathing techniques } \\
\text { RAIN training }\end{array}$ \\
\hline
\end{tabular}

RAIN = recognizing what is going on, allowing the experience to be as it is, investigate with kindness, and natural awareness or non-judgment

Table 2. Impact of Mindfulness Intervention on Distress Scales and Breathing Rates

\begin{tabular}{|c|c|c|c|c|c|}
\hline \multirow{2}{*}{ Cohort } & \multirow{2}{*}{ Measure } & \multicolumn{3}{|c|}{ Median (interquartile range) } & \multirow{2}{*}{$P$} \\
\hline & & Before & After & Difference & \\
\hline \multirow[t]{2}{*}{ Session 1} & Distress scale score & $5(3-6)$ & $4(2-5)$ & $-1(-1$ to 0$)$ & .001 \\
\hline & Breathing rate & $9(6.8-10)$ & $6(5-7.5)$ & $-2(-3.6$ to -1$)$ & .001 \\
\hline \multirow[t]{2}{*}{ Session 2} & Distress scale score & $5.5(3-6.3)$ & $5(3-6.3)$ & $-1(-2$ to 0$)$ & .39 \\
\hline & Breathing rate & $10(6-14)$ & $8(6-12)$ & $-2(-2$ to 0$)$ & .001 \\
\hline
\end{tabular}

During session 2, the facilitator provided a review of mindfulness and offered space for any questions or comments since the previous session. The 2:1 breathing technique was taught during this session. In short, it is a breathing exercise in which the exhalation is twice the length of the inhalation, therefore, slowing the exhaled phase. This slowing down has been found to create a calming effect on the body and mind. Next, the facilitator discussed the concept of self-compassion according to Dr Kristin Neff, $\mathrm{PhD} .{ }^{17}$ Self-compassion was defined as including the concepts of self-kindness, common humanity, and mindfulness. The facilitator then explained how to use Dr Neff's ${ }^{18}$ self-compassion break.

The self-compassion break encourages participants to use mindfulness and self-compassion ${ }^{19}$ in times of difficulty or stress such as in the setting of a high-stress critical-care intubation moment or when caring for a child with intractable asthma in an emergency setting. The first step is to recognize the moment by saying to one's self "this is a moment of suffering." Next, common humanity is identified by silently saying "suffering is a part of human life." Finally, kindness is practiced when a person says to one's self "may I be kind to myself." The final technique shared was the mindfulness practice of RAIN. RAIN is an acronym for R, recognizing what is going on; A, allowing the experience to be as it is; I, investigate with kindness; and $\mathrm{N}$, natural awareness or non-judgment. These 4 steps support a mindfulness practice in times of distress and in times of caring well for others during high-stress moments. The acronym was put on a card the size of a hospital name badge and given to each participant to reference after the sessions.

Due to the possibility that some participants were represented in both months (the possibility of the same subjects in both cohorts), the summary and analysis were done by cohort rather than on individual RT level. Data were summarized as the median and interquartile range for the before, after, and paired differences. Due to the relatively low sample size, the Wilcoxon signedrank test was used to compare pre- and post-intervention scores.

\section{Results}

A total of 40 RTs participated in session 1, and 24 participated in session 2 (the difference in participation was based on staff meeting attendance rates). The distress scores were noted to decrease by one full point in session 1 $(P=.001)$ and in session $2(P=.39)$. The breathing rate decreased by 2 points before and after the mindfulness intervention during both sessions $(P=.001)$. A summary of the impact is provided in Table 2 and Figure 1. Distress scores and breathing rates were not found to differ by an RT's sex, years in practice, or medical care setting. Patient impact metrics were not part of the study.

\section{Discussion}

This quality-improvement project revealed that integration of mindfulness-based interventions as part of RT staff 


\section{Mindfulness to Support RT ResilienCy}
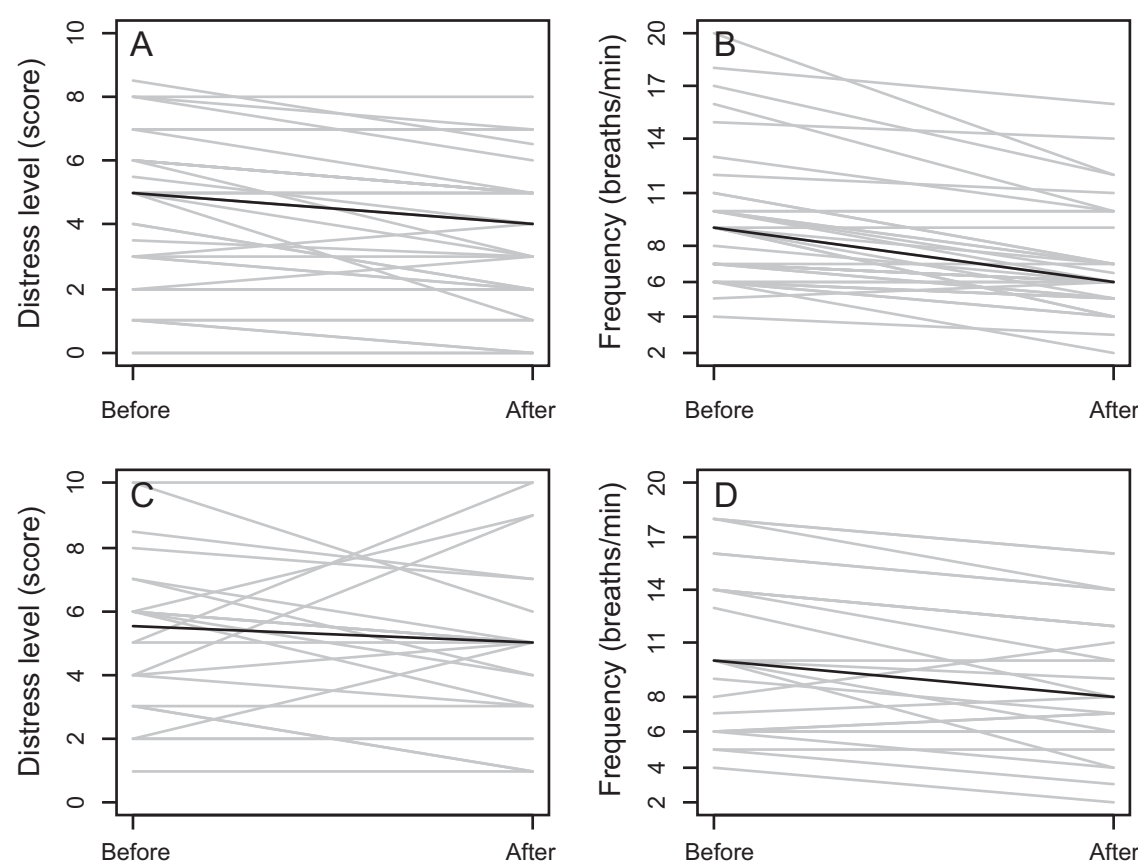

Fig. 1. Impact of mindfulness-based interventions on distress scores and breathing frequency. A: Distress level of the November cohort. B: Breathing frequency of the November cohort. C: Distress level of the March cohort. D: Breathing frequency of the March cohort.

meetings decreased RT team members' physical and emotional stress-related symptoms (as measured by a self-administered Distress Thermometer assessment) and increased RT team members' sense of calm (as measured by participants' breathing rate). Competencies that developed through this intervention included breathing practices that can be done in the RT work environment and mini mindfulness techniques to be used in the work environment. Although RTs spend the majority of each work day helping others breathe and breathe well, we were not able to find literature on mindfulness curricula for respiratory relaxation specific for RTs for self-care or for professional care.

The mindfulness-based intervention was selected based on a review of available offerings with the hospital resiliency committee, palliative care, and behavioral health representatives locally. Calm breathing-based interventions were selected based on discussions with the RT leadership team on what form of mindfulness care would be feasible during staff meetings. Other interventions considered were tai chi or gentle yoga, but these were determined to not be ideal due to varying health status of participating RT members (not wanting members to feel uncomfortable if they were unable to fully participate in the stretches or positions due to physical restrictions). Biofeedback was considered, but there was a decision not to include direct biofeedback due to limited access to enough skin, heart rate, and respiratory monitors to ensure that all RT staff members had a machine during the intervention.
Strengths of this study included attentiveness to a high-stress staff role in the hospital for professional resiliency and team care, and a 2-time-point care intervention. Weaknesses of this study included the singlesite location and lack of longitudinal outcomes comparison with a control group. Future study opportunities include (a) longitudinal metrics beyond the immediate pre- and post-intervention time points, (b) analysis of the impact on staff retention and job satisfaction, and (c) investigation of ways that mindfulness training for the RT team members translates into mindful breathing interventions at the bedside of patients and parents to include patient safety impact.

Mindfulness-based interventions were noted to be feasible and acceptable additions to RT staff meetings as part of self-care and as part of team care. The ultimate goal of this care intervention was to decrease the experience of burnout or compassion fatigue by empowering RTs with relaxation breathing exercises with the hope that they could bring these techniques into their own self-care practice in addition to their professional practice at the bedside of pediatric patients and families. As summarized by one RT member, "now, when I administer a nebulized treatment to a scared child in the emergency room, instead of standing there and impatiently tapping my foot waiting for the medicine to dissolve - I now gently say to the child "breathe in calm, breathe in peace, breathe out fear, breathe out discomfort, breathe in compassion' and I realize that I am truly healing and not just treating." 


\section{Mindfulness to SuPPORT RT RESILIENCY}

\section{Conclusions}

True to the meaning of pneuma as life breath, spirit, or vital force that gives animation, energy, or principal, Pneuma Care as a quality-improvement project strove to collectively energize the RT team and to enhance the RT team members' personal mindfulness skill set.

\section{REFERENCES}

1. Metcalf AY, Stoller JK, Habermann M, Fry TD. Respiratory therapist job perceptions: the impact of protocol use. Respir Care 2015; 60(11): 1556-1559.

2. Schwabbauer N. [The respiratory therapist in the intensive care unit team]. Med Klin Intensivmed Notfmed 2014;109(3):191-195.

3. Blake SS, Kester L, Stoller JK. Respiratory therapists' attitudes about participative decision making: relationship between managerial decision-making style and job satisfaction. Respir Care 2004;49(8): 917-925.

4. Shelledy DC, Mikles SP, May DF, Youtsey JW. Analysis of job satisfaction, burnout, and intent of respiratory care practitioners to leave the field or the job. Respir Care 1992;37(1):46-60.

5. Akroyd HD, Robertson R. Factors affecting the job satisfaction of respiratory therapists who work in adult general and critical care: a multivariate study. Respir Care 1989;34(3):179-184.

6. Daigle S, Talbot F, French DJ. Mindfulness-based stress reduction training yields improvements in well-being and rates of perceived medical errors among hospital nurses. J Adv Nurs 2018;74(10):24272430.

7. Valley MA, Stallones L. Effect of Mindfulness-Based Stress Reduction Training on Health Care Worker Safety: A Randomized Waitlist Controlled Trial. J Occup Environ Med 2017;59(10):935-941.

8. Penprase B, Johnson A, Pittiglio L, Pittiglio B. Does mindfulnessbased stress reduction training improve nurse satisfaction? Nurs Manage $2015 ; 46(12): 38-45$.
9. Hallman IS, O'Connor N, Hasenau S, Brady S. Improving the culture of safety on a high-acuity inpatient child/adolescent psychiatric unit by mindfulness-based stress reduction training of staff. J Child Adolesc Psychiatr Nurs 2014;27(4):183-189.

10. Barbosa P, Raymond G, Zlotnick C, Wilk J, Toomey R III, Mitchell J III. Mindfulness-based stress reduction training is associated with greater empathy and reduced anxiety for graduate healthcare students. Educ Health (Abingdon) 2013;26(1):9-14.

11. Ribeiro Santiago PH, Colussi CF. Feasibility evaluation of a mindfulness-based intervention for primary care professionals: Proposal of an evaluative model. Complement Ther Clin Pract 2018;31:57-63.

12. MacCoon DG, Imel ZE, Rosenkranz MA, Sheftel JG, Weng HY, Sullivan JC, et al. The validation of an active control intervention for Mindfulness Based Stress Reduction (MBSR). Behav Res Ther 2012; 50(1):3-12.

13. Donovan KA, Grassi L, McGinty HL, Jacobsen PB. Validation of the Distress Thermometer worldwide: state of the science. Psychooncology 2014;23(3):241-250

14. Antoniadis D, Lavrentiadis G, Papadopoulos VN, Ierodiakonou I, Garyfallos G. The validity of the Distress Thermometer in Greek colon cancer patients. Acta Chir Belg 2015;115(6):387-392.

15. Chambers SK, Zajdlewicz L, Youlden DR, Holland JC, Dunn J. The validity of the Distress Thermometer in prostate cancer populations. Psychooncology 2014;23(2):195-203.

16. Iskandarsyah A, de Klerk C, Suardi DR, Soemitro MP, Sadarjoen SS, Passchier J. The Distress Thermometer and its validity: a first psychometric study in Indonesian women with breast cancer. PLoS One 2013;8(2):e56353.

17. Neff KD. Self-compassion: an alternative conceptualization of a healthy attitude toward oneself. Self and Identity 2003;2:85-102.

18. Neff KD. The role of self-compassion in development: a healthier way to relate to oneself. Human Development 2009;52:211-214.

19. Neff KD, Lamb LM. Self-Compassion. In: The Encyclopedia of Positive Psychology, Lopez S, editor. Oxford: Blackwell Publishing; 2009:864-867. 